\title{
Gomez-López-Hernandez syndrome: the triad of cerebello-trigemino-dermal dysplasia
}

\author{
Neha Choudhary (1), 'Anuj Prabhakar 지, 'Vikas Bhatia, ${ }^{1}$ Parul Chawla Gupta ${ }^{2}$
}

${ }^{1}$ Department of Radiodiagnosis and Imaging, Post Graduate Institute of Medical Education and Research, Chandigarh, India ${ }^{2}$ Department of Ophthalmology, Post Graduate Institute of Medical Education and Research, Chandigarh, India

\section{Correspondence to}

Dr Anuj Prabhakar;

dranujprabhakar@gmail.com

Accepted 2 October 2021

\section{DESCRIPTION}

A 14-year-old female presented with progressive diminution of vision in the right eye. She had leftsided loss of vision since 1 year of age. The patient had aggressive behaviour with irrelevant talking. She was intellectually disabled and had a history of delayed motor and language milestones. On examination, she was short-statured and had craniofacial abnormalities in the form of midface retrusion, flat nasal bridge, low-set ears, widened philtrum, thin upper lip vermillion and hypertelorism (figure 1A). The left eye was phthisic and corneal opacity was seen in the right eye (figure 1B,C). Bilateral corneal reflexes were absent. There was partial sensory loss in the distribution of ophthalmic division (V1) of bilateral trigeminal nerves. Bilateral parietotemporal alopecia (figure 1D,E) and forehead scarring (figure 1A) were present. Cerebellar signs were present in the form of difficulty in tandem gait and dysmetria.

MRI of the brain revealed a small posterior fossa. Vermis and falx cerebelli were absent with fusion of bilateral hypoplastic cerebellar hemispheres and midline continuation of folia suggestive of rhombencephalosynapsis (RES) (figure 2A,B). There was fusion of bilateral superior cerebellar peduncles and thalami (figure 2C,D). Bilateral middle cerebellar peduncles were anteroposteriorly directed.

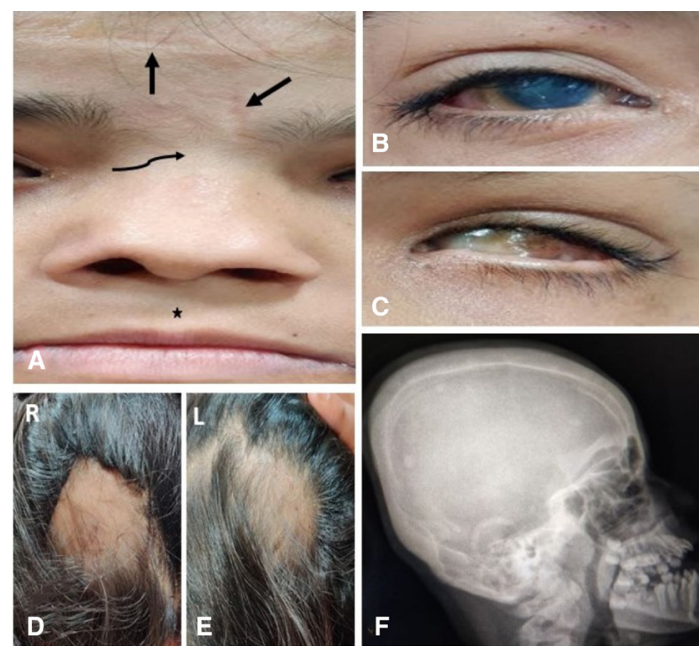

C) BMJ Publishing Group Limited 2021. No commercial re-use. See rights and permissions. Published by BMJ.

To cite: Choudhary $\mathrm{N}_{\text {, }}$ Prabhakar A, Bhatia V, et al. BMJ Case Rep

2021;14:e246189.

doi:10.1136/bcr-2021-

246189

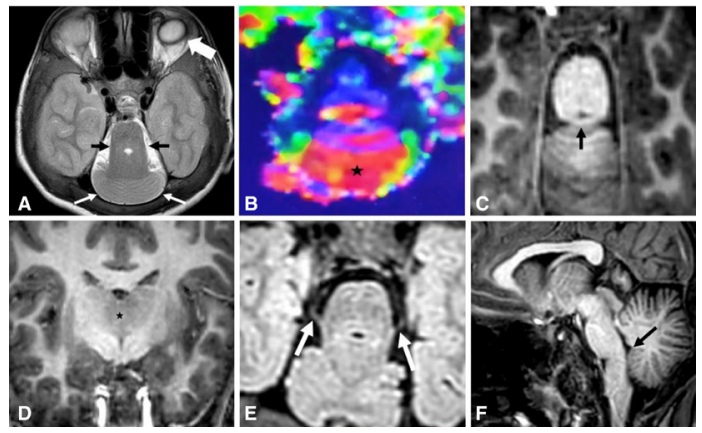

Figure 2 (A) T2-weighted axial image shows small posterior fossa with small cerebellum, absent vermis and midline continuation of cerebellar folia (thin white arrows). Bilateral middle cerebellar peduncles are anteroposteriorly directed (black arrows). Left eye is phthisic with distorted globe (thick white arrow). (B) Fractional anisotropy directional map shows left to right directed red fibres extending across cerebellum (asterisk). (C) T1-weighted axial image shows fusion of bilateral superior cerebellar peduncles (black arrow). (D) T1weighted coronal image shows midline fusion of thalami (asterisk). (E) Axial reconstruction of three-dimensional Fluid-attenuated inversion recovery (FLAIR) image shows hypoplastic bilateral trigeminal nerves ( $L>R$ ) (arrows). (F) T1-weighted sagittal image shows abnormal fourth ventricle with bumpy roof and low-lying fastigium (black arrow).

Bilateral trigeminal nerves were small in size $(\mathrm{L}>\mathrm{R})$ (figure 2E). The fourth ventricle was abnormal with low-lying fastigium (figure $2 \mathrm{~F}$ ). Brachyturricephalic skull with diffuse calvarial thickening was seen (figure 1F).

The patient's clinical and imaging findings suggested a diagnosis of Gomez-López-Hernandez syndrome (GLHS), also known as cerebellotrigemino-dermal dysplasia. It is a rare neurocutaneous syndrome, and approximately 73 cases have been reported to the best of our knowledge. ${ }^{1}$ GLHS is characterised by triad of RES, partial alopecia and trigeminal anaesthesia. However, trigeminal anaesthesia is present only in $50 \%-60 \%$ of cases. In the absence of trigeminal anaesthesia, the presence of other craniofacial abnormalities can also suggest the diagnosis of GLHS. ${ }^{3}$ Craniofacial abnormalities include brachyturricephaly, midface retrusion, hypertelorism, widened philtrum and low-set ears. Other clinical features include intellectual disability, motor delay, strabismus, ataxia, hypotonia, seizures and characteristic head shaking in 'figure-of-eight' pattern. Our patient did not have seizures or any stereotypical movements. Trigeminal anaesthesia 
can cause repeated unaware injuries which can lead to forehead scarring, corneal opacities and phthisis bulbi in severe cases. Aqueduct stenosis, hydrocephalus, absent septum pellucidum, absent olfactory bulbs, absent or hypoplastic trigeminal nerves, and dentate or tonsillar fusion can also be seen. Other systemic abnormalities such as absent kidney, neurogenic bladder, cryptorchidism and hypoplastic labia majora can also be associated.

The genetic basis of GLHS is still unknown. Defects in dorsoventral patterning can give rise to RES. GLHS is the most common syndromic association of RES. ${ }^{4}$ Insult to the embryo at

\section{Patient's perspective}

Our daughter, who is the eldest among four siblings, had difficulty in learning walking and language. Her left eye got damaged when she was 1 year old. Now she is having vision problems in the right eye also. She falls frequently and has had many injuries. We had taken her to several doctors who had asked us to go to higher centres for treatment, but because of financial issues, we could not provide her treatment. Now we want to at least save her right eye so that her quality of life does not worsen further.

\section{Learning points}

- Gomez-López-Hernandez syndrome or cerebllo-trigeminodermal dysplasia is a neurocutaneous syndrome characterised by rhombencephalosynapsis, partial alopecia, and trigeminal anaesthesia or other craniofacial abnormalities.

- Trigeminal anaesthesia can cause loss of vision secondary to repeated unaware eye injuries, leading to corneal opacities or phthisis bulbi in severe cases.
28-44 days can cause developmental arrest of part of ectoderm from which alar plate of rhombencephalon, overlying epidermis, trigeminal nucleus and trigeminal placodes arise, which can give rise to constellation of findings of GLHS. ${ }^{5}$ There have been reports of GLHS in children of mothers with misoprostol exposure in first trimester, substance abuse, assisted reproduction and maternal diabetes, which suggest the role of environmental and epigenetic mechanisms in its pathogenesis. ${ }^{16}$

Contributors NC was involved in concept and design, patient management, literature review, data collection and manuscript preparation. AP was involved in concept, patient management, literature review, manuscript review and supervision. VB was involved in concept, manuscript review and supervision. PCG was involved in patient management, manuscript review and supervision.

Funding The authors have not declared a specific grant for this research from any funding agency in the public, commercial or not-for-profit sectors.

Competing interests None declared.

Patient consent for publication Consent obtained from parent(s)/guardian(s)

Provenance and peer review Not commissioned; externally peer reviewed.

\section{ORCID iDs}

Neha Choudhary http://orcid.org/0000-0002-4097-0736

Anuj Prabhakar http://orcid.org/0000-0002-5636-6517

\section{REFERENCES}

1 Perrone E, Perez ABA, D'Almeida V, et al. Clinical and molecular evaluation of 13 Brazilian patients with Gomez-López-Hernández syndrome. Am J Med Genet A 2021;185:1047-58

2 Rush ET, Adam MP, Clark RD, et al. Four new patients with Gomez-Lopez-Hernandez syndrome and proposed diagnostic criteria. Am J Med Genet A 2013;161A:320-6.

3 Sukhudyan B, Jaladyan V, Melikyan G, et al. Gómez-López-Hernández syndrome: reappraisal of the diagnostic criteria. Eur J Pediatr 2010;169:1523-8.

4 Ishak GE, Dempsey JC, Shaw DWW, et al. Rhombencephalosynapsis: a hindbrain malformation associated with incomplete separation of midbrain and forebrain, hydrocephalus and a broad spectrum of severity. Brain 2012;135:1370-86

5 Gomez MR. Cerebellotrigeminal and focal dermal dysplasia: a newly recognized neurocutaneous syndrome. Brain Dev 1979;1:253-6.

6 Aldinger KA, Dempsey JC, Tully HM, et al. Rhombencephalosynapsis: fused cerebellum, confused geneticists. Am J Med Genet C Semin Med Genet 2018;178:432-9.

Copyright 2021 BMJ Publishing Group. All rights reserved. For permission to reuse any of this content visit

https://www.bmj.com/company/products-services/rights-and-licensing/permissions/

BMJ Case Report Fellows may re-use this article for personal use and teaching without any further permission.

Become a Fellow of BMJ Case Reports today and you can:

- Submit as many cases as you like

- Enjoy fast sympathetic peer review and rapid publication of accepted articles

- Access all the published articles

Re-use any of the published material for personal use and teaching without further permission

Customer Service

If you have any further queries about your subscription, please contact our customer services team on +44 (0) 2071111105 or via email at support@bmj.com.

Visit casereports.bmj.com for more articles like this and to become a Fellow 